\title{
Transition care in Hong Kong
}

\author{
Keith K Lau *, FHKCPaed, FHKAM (Paediatrics) \\ Department of Paediatrics, The University of Hong Kong-Shenzhen Hospital, No. 1, Haiyuan 1st Road, Futian District, Shenzhen, \\ China 518053 \\ *keithklau@hku-szh.org \\ Hong Kong Med J 2016;22:408-9 \\ DOI: 10.12809/hkmj165060
}

The main objective of the transition from paediatric to adult health care services is to ensure that all adolescents continue to receive coordinated care after reaching adulthood. ${ }^{1}$ Medical personnel understand that when children grow up, there are adulthoodrelated issues such as pregnancy or drug-related illnesses that many paediatricians are not equipped to deal with. Thus, transferring patient care to adult facilities is often an essential and unavoidable event in the medical journey for children.

There is now ample evidence that children who acquire a major physical illness at an early age, such as chronic kidney disease, are also at risk of cognitive developmental delays. ${ }^{2}$ Thus, while all youths eventually experience transition in health care, paediatricians are particularly concerned about youths with physical and/or cognitive disabilities. Medical care for these individuals is often more complex: they will generally also need long-term therapies and require extra attention due to the accompanying suboptimal cognitive maturity. In order for their health care to successfully transition to adult facilities, it is crucial that these vulnerable youths receive sufficient and appropriate preparation.

Although the literature suggests that many children with physical and cognitive disabilities suffer profound and prolonged morbidities due to ineffective health care transitioning, paediatric caregivers in Hong Kong face wideranging predicaments both within and outside the health care system. Problems include the lack of a comprehensive health care policy, scarcity of transition programmes, inadequate physician training, and inadequate education and preparation of patients and/or their family. In "A proposal on child health policy for Hong Kong" published by the Hong Kong Paediatric Society in August 2015, paediatric health care professionals expressed their desire to set up and implement a comprehensive, yet effective child health care policy to address the many health care challenges in Hong Kong. The professional panel pointed out that among all major concerns, there was ultimately a lack of coordinated and uninterrupted care for children with special care needs and medical complexities. In particular, the transition of care for such children was especially fragmented.

Transition preparations for children with special needs have been a public concern in many developed countries. ${ }^{4}$ The US Government has also identified the need to involve more physicians in transition planning as a public health objective in the Healthy People 2020 project. $^{4,5}$

Efforts have been made to develop transition programmes, for example, with the establishment of transition clinics that are directed by transition coordinators in conjunction with adult-care physicians. ${ }^{6}$ During the past decade, more and more organisations have taken the initiative to set up 'Family-Centered Medical Homes' in order to integrate care for children with special needs. ${ }^{4}$

In 2011, the Transitions Clinical Report Authoring Group, along with representatives from the American Academy of Pediatrics, the American Academy of Family Physicians and the American College of Physicians, issued a clinical report on the practice-based implementation of transition for youth. ${ }^{7}$ The report offered a framework for training not only for the medical team, but also for educators, assistants, and families of youths in medical homes. This year, the National Institute for Health and Care Excellence in England also published their guidelines on the transition of care for young people. ${ }^{8}$ They provide practical advice for caregivers attempting to improve young people's engagement with services.

There are also some other transition tools available through the Internet that may be able to be adapted for use in education for the general public or even as a means to assess whether patients are ready for health care transitions. ${ }^{9}$ One such tool that could be particularly beneficial is the MyHealth Passport, ${ }^{10}$ as well as other tools listed in the Health Care Transition Resources. ${ }^{11}$ Since children with special needs are heterogeneous in nature, there is currently no universal tool although most tools can potentially be customised for each individual child and his/her family according to cultural background and underlying disabilities.

In 2007, approximately 10900 adolescents with disabilities between the ages of 14 and 17 years took part in the Survey of Adult Transition and Health. ${ }^{12}$ The results showed that only $21.6 \%$ of adolescents had undergone successful transition to adult care. This finding reflects the dire fact that despite all the efforts made, the health care system in its current state still fails to support the majority of youths with 
special needs who are exiting paediatric care. There remains a great need for research and evaluation on the outcome of the transition of children with disabilities into adult facilities.

In the current issue, Pin et $\mathrm{al}^{13}$ reports on their local pilot data on the clinical transition of adolescents with developmental disabilities. Among the surveyed children and their families, approximately $60 \%$ considered the transfer process to be suboptimal. Although the study was confounded by many limitations and the findings are far from conclusive, it sheds light on the underlying causes of dissatisfaction and hurdles associated with youth transition in Hong Kong. Since a solid understanding of the underlying problems is important in finding a solution, we desperately need more local and relevant information on how to improve the effectiveness and success of health care transfer for children with special needs.

One of the six core goals of the care of children with special needs, as identified by the Maternal and Child Health Bureau, is to ensure that these individuals continue to receive the support necessary for transitioning to adulthood. ${ }^{14}$ The ultimate goal is not just to provide the necessary medical care during transition, but also to enable individuals to succeed in all aspects of life so that they are able to work, to assimilate into society, and to achieve independence.

Now that the deficiencies have been identified, it is time for medical professionals to take the initiative and work together to help shape the future of health care for children with special needs.

\section{References}

1. Davis AM, Brown RF, Taylor JL, Epstein RA, McPheeters ML. Transition care for children with special health care needs. Pediatrics 2014;134:900-8.

2. Johnson RJ, Warady BA. Long-term neurocognitive outcomes of patients with end-stage renal disease during infancy. Pediatr Nephrol 2013;28:1283-91.

3. The Hong Kong Paediatric Society, The Hong Kong Paediatric Foundation, and Child Healthcare Professionals in Hong Kong. A proposal on child health policy for
Hong Kong. 2015. Available from: http://hkpf.org.hk/ download/20150920 Child Health Policy for Hong Kong_ Final.pdf. Accessed Aug 2016.

4. McManus MA, Pollack LR, Cooley WC, et al, Current status of transition preparation among youth with special needs in the United States. Pediatrics 2013;131:1090-7.

5. Office of Disease Prevention and Health Promotion. 2020 Topics \& Objectives: Disability and Health. Available from: https://www.healthypeople.gov/2020/topics-objectives/ topic/disability-and-health/objectives. Accessed Aug 2016.

6. McQuillan RF, Toulany A, Kaufman M, Schiff JR. Benefits of a transfer clinic in adolescent and young adult kidney transplant patients. Can J Kidney Health Dis 2015;2:45.

7. American Academy of Pediatrics; American Academy of Family Physicians; American College of Physicians; Transitions Clinical Report Authoring Group, Cooley WC, Sagerman PJ. Supporting the health care transition from adolescence to adulthood in the medical home. Pediatrics 2011;128:182-200.

8. NICE Pathway-Transition from children's to adults' services for young people using health or social care services. NICE Guideline 43. 24 February 2016. Available from: https://www.nice.org.uk/guidance/NG43. Accessed Aug 2016.

9. Schwartz LA, Daniel LC, Brumley LD, Barakat LP, Wesley KM, Tuchman LK. Measures of readiness to transition to adult health care for youth with chronic physical health conditions: a systematic review and recommendations for measurement testing and development. J Pediatr Psychol 2014;39:588-601.

10. The Hospital for Sick Children, Good 2 Go Transition Program-MyHealth Passport. Available from: https:// www.sickkids.ca/myhealthpassport/. Accessed Aug 2016.

11. Got Transition. Health care transition resources. Available from: http://www.gottransition.org/resources/. Accessed Aug 2016.

12. Oswald DP, Gilles DL, Cannady MS, Wenzel DB, Willis $\mathrm{JH}$, Bodurtha JN. Youth with special health care needs: transition to adult health care services. Matern Child Health J 2013;17:1744-52.

13. Pin TW, Chan WL, Chan CL, et al. Clinical transition for adolescents with developmental disabilities in Hong Kong: a pilot study. Hong Kong Med J 2016;22:445-53.

14. US Department of Health and Human Services. The National Survey of Children with Special Health Care Needs Chartbook 2005-2006. Rockville: Department of Health and Human Services; 2008. 